\title{
"Cuatro paredes de agua». Intervención de César Barrio en el Lavadero de las Francesinhas de Lisboa
}

\author{
Del 9 al 31 de mayo de 2019
}

"Cuatro paredes de agua» es un proyecto multidisciplinar del artista César Barrio (Oviedo 1971), con producción y comisariado de Leonor Pereira y coordinación de Vicky Úrculo, que orbita alrededor de una intervención sensorial realizada del 9 al 31 de mayo de 2019 en el Lavadero de las Francesinhas, ubicado en el barrio lisboeta de Madragoa. Lisboa ocupa un lugar recurrente en el imaginario creador de César Barrio. Más bien, ese lugar lo colonizan los rincones escondidos que contienen, atrapados en su presencia, una acumulación de capas de historia, estratos que constituyen la esencia del ser humano que los ha ido conformando. $Y$ Lisboa es un lugar pródigo en cuanto a lugares llenos de huellas de vida, un lugar que César conoce bien y que explora en su avidez de vestigios del paso del ser humano, rastros que forman la tinta y la sangre de sus posteriores creaciones. En una de sus expediciones, pues solo así se pueden llamar sus viajes realizados con ojos y análisis escudriñadores, el artista se topa con el Lavadero de las Francesinhas, un espacio cuya longeva historia estaba a punto de tocar a su fin debido a un proyecto de remodelación y construcción que contemplaba su destrucción. Con la intervención que desarrolla, César ha buscado no solo dar visibilidad al conjunto antes de su desaparición sino aprehender la esencia del significado del lugar, de sus historias atrapadas y, no sin un ánimo utópico que la visión artística conlleva inherente, poner al descubierto una posibilidad de replantearse la desaparición del espacio nacido en 1876.

"Cuatro paredes de agua» se conforma como una integración visual de creaciones pictóricas basadas en transparencias lumínicas en el espacio que las acoge, funcionando desde todos los posibles puntos de vista. Como es habitual en su creación, César rompe el discurso bidimensional de la creación pictórica, esta vez construyendo tridimensionalmente a través de la disposición de los pane- les y de las transparencias que permite el metacrilato con que sustenta su intervención. Siguiendo el trazado arquitectónico que rige la funcionalidad del edificio, ha suspendido por medio de una estructura metálica una serie de paneles verticales, ropa tendida evocada, rodeando tangencialmente las láminas de agua de las pilas del lavadero. Estos ocho paneles transparentes, de doce por dos metros cada uno, han sido intervenidos con color trabajado desde su génesis con las directrices de la verticalidad hacia la que estaban destinadas. La gravedad guía sus direcciones hacia las láminas de agua que bajo ellos esperan. Una suerte de códigos de barras teñidos, manantiales que bajan lentamente, como discurre el tiempo en Lisboa, una armonía de tonalidades controladamente fortuitas, paralelas cuya verticalidad inquieta a la horizontalidad del edificio y de sus aguas, permiten a la luz ser matizada y cruzar sus huellas impregnándose de sus colores. Sobre ellas, nebulosas de pigmentos pulverulentos flotan livianas trasladando nuestra visión desde la gravedad hacia la percepción de su ausencia, evocando galaxias y microcosmos donde se ralentiza, aún más si cabe, el tiempo lisboeta. Aquí, sin una necesidad mimética, sin pretensión de imitar la imagen de forma y color que nos muestra la naturaleza, César crea su mundo sobre las leyes internas que existen en la distribución de las fuerzas físicas que llevan a la conformación y equilibrio de los macro y micro mundos, tanto de galaxias y demás formaciones cósmicas como de los mundos microscópicos que conforman la realidad interna de lo existente. Para César este cambio de escalas es algo inherente a la abstracción en la pintura [1].

Construido el artificio, la luz entra en acción acompañada del silencioso rumor de las aguas que recorren las pilas, del delicado murmullo del caño que cruza de pila en pila. Inspirado por el agua del Tajo, que no solo talla la ciudad

Cómo citar este artículo: MARTíNEZ PÉREZ, Javier, "Cuatro paredes de agua". Intervención de César Barrio en el Lavadero de las Francesinhas de Lisboa", Boletín de Arte-UMA, n. ${ }^{\circ}$ 42, Departamento de Historia del Arte, Universidad de Málaga, 2021, pp. 363-366, ISSN: 0211-8483, e-ISSN: 2695-415X, DOI: http://dx.doi.org/10.24310/ BoLArte.2021.vi42.11748 


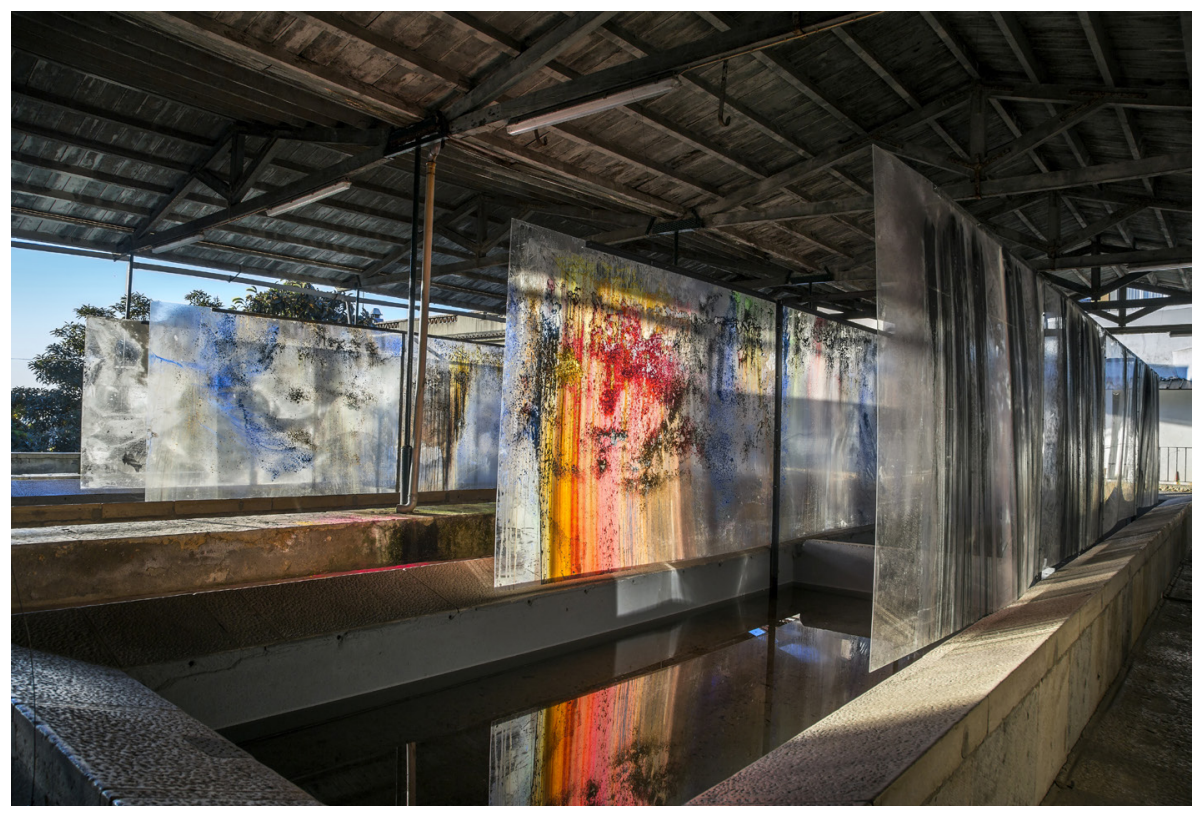

con su transcurso protagonista, si no que habita las calles de Lisboa en forma de luz, de un reflejo que rebota por sus rincones inundando la esencia de sus espacios, la luz entra en la obra tamizada por el universo de color creado por el artista. Se refleja en la superficie del agua para atravesar el siguiente panel y vibrar sobre los grises de las piedras de las pilas y las maderas del artesonado de la cubierta. La distribución de los espacios de la instalación de César consigue sumergir al espectador en el recorrido por un espacio tridimensional pausado, ocupado por el color que trasciende los paneles para habitar el lugar donde los sonidos marcan el ritmo, como un metrónomo que ordenase la serenidad que impera en el lugar. Son múltiples los sonidos que envuelven el conjunto, desde el citado rumor del discurrir de las aguas hasta el canto de las aves que se acercan en busca del agua, el frescor o el cobijo de sus techos. La característica arquitectura decimonónica, la ubicación del lavadero y la distribución de las paredes de agua permiten, de un modo mágico, que hasta los lejanos sonidos de la civilización que llegan al lugar suenen armónicos y sugestivos. Estos ambientes sensoriales quedan reflejados, y así lo podemos percibir, en los audiovisuales que complementan el proyecto artístico, como el vídeo del mismo título producido por $\mathrm{Na-}$ cho Chueca (2020) [2].
Al igual que lo hacen sus sonidos, la ciudad interviene como imagen a través del juego de espejos que se produce entre las superficies de los paneles y las del agua, provocando la desaparición de la corporeidad de la propuesta. Las arquitecturas y sus perfiles recortados contra el cielo, las gentes en sus desplazamientos, la arboleda urbana o los múltiples cables que trenzan un entramado de grafías, son difuminadas tras los paneles y reflejadas en el agua para ser percibidas como parte de la obra.

Esta experiencia visual y sonora que se dirige al ámbito sensorial del espectador se cimenta sobre el análisis de conceptos como la huella, la presencia y los rituales asociados a ellas. Como todo suceso relativo a la existencia, las actividades humanas dejan una huella que perdura y trasciende el punto temporal en que estas se producen. Dentro del infinito conjunto de huellas que rasgan nuestro entorno, aquellas que delatan la presencia del ser humano han derivado en múltiples ocasiones en rituales que evocan, rememoran, homenajean, aprenden e incluso convocan a aquellos que las causaron. Dejando esa puerta abierta, César no entra a desentrañar el crucigrama de los sucesos y sus circunstancias, sino más bien nos ofrece aquella "erótica del arte» a la que apela Susan Sontag en su ensayo Contra la interpretación: «En lugar de una hermenéutica, necesitamos una erótica del 

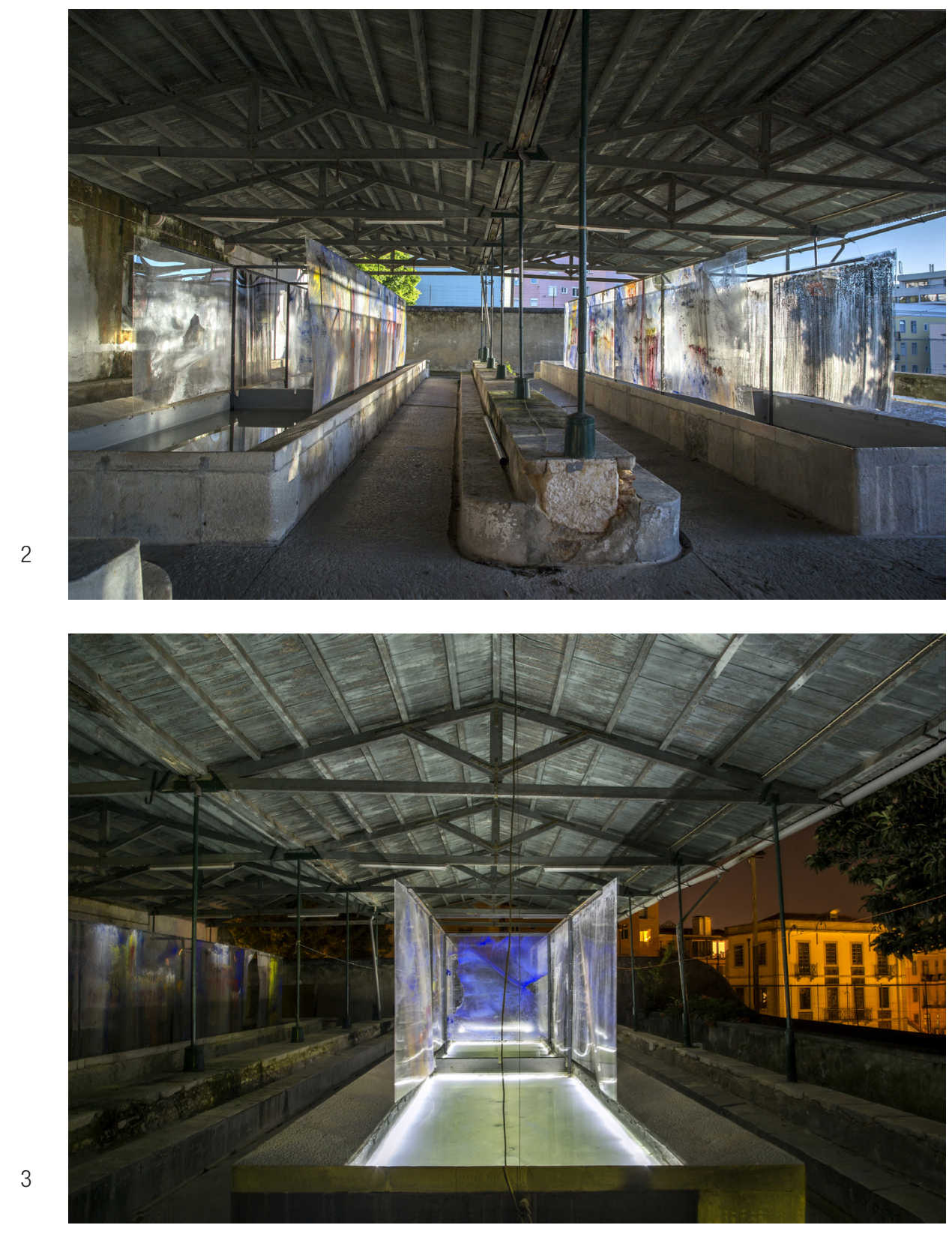

arte» (1984: 27). El Lavadero, como lugar de encuentro de distintas generaciones a lo largo de muchos años, ha sido cobijo y es testigo de historias, de actos, ya sean banales o trascendentes, que han dejado la huella de una cultura, un modo de vida, una realidad. Ese testigo mudo que, de algún modo, se halla presente tanto en los elementos estáticos erigidos por la mano del hombre como en los de la naturaleza que los habitan, es dotado de voz, de un poderoso cauce de comunicación como es la creación artística. De este modo, la intervención incita al espectador a penetrar en un mundo de sonidos, luces, colores, brisas y estímulos que permiten evocar, dentro de las experiencias y predisposiciones de cada uno de nosotros, historias, vidas y sucesos que habitan los espacios hasta entonces incógnitos y discretos [3].

Dentro de la multidisciplinariedad del proyecto, este se ha visto complementado con otras actuaciones como el con- 
cierto Fado pintado, de Marco Oliveira y Manel Ferreira, con pintura en directo del autor, realizado el 25 de mayo en el propio espacio intervenido del Lavadero, también con el citado video de Nacho Chueca, que forma parte de la serie de televisión documental Territorio Gravedad, producida por Lipssync Medialab SRL, promovido por la Sociedad Española de Gravitación y Relatividad (SEGRE), enmarcado dentro del Consejo Superior de Investigaciones Científicas (CSIC), así como con la edición de una publicación en formato físico del catálogo homónimo, aún en proceso de producción.

El proyecto cuenta con la colaboración de la Embajada de España en Portugal, la Cámara Municipal de Lisboa, la Freguesía de Estrela, el Centro Portugués de Serigrafía y la Assistência Paroquial de Santos-o-Velho.
César Barrio nace en Oviedo en 1971. Licenciado en arquitectura en 2004, ha desarrollado su carrera profesional como artista plástico, realizando su primera exposición en 1989. Ha sido profesor invitado en las diversas escuelas de arquitectura impartiendo cursos y conferencias. Como artista multidisciplinar, es colaborador habitual de estudios de arquitectura, escritores, músicos, poetas, escenógrafos o diseñadores de moda, entre otros proyectos inclasificables. Vive y desarrolla su labor artística entre Madrid y Lisboa, cuando no se desplaza por otras geografías buscando nuevos objetivos.
Javier Martínez Pérez

Universidad Complutense de Madrid

\section{Bibliografía}

BARCELÓ, Carlos y CHUECA, Nacho, «Territorio gravedad». En: territorio gravedad ESP (gravityland.eu) (fecha de consulta: 29-01-2021). BARRIO, César, «César Barrio». En: Home | cesarbarrio (wixsite.com) (fecha de consulta: 29-01-2021).

CHUECA, Nacho, «Quatro paredes de agua». En QUATRO PAREDES DE AGUA César Barrio. Lisboa, Maio 2019-YouTube (fecha de consulta: 29-01-2021).

SONTAG, Susan (1966-1984), Contra la interpretación y otros ensayos. Traducido por Horacio Vázquez Rial, Seix Barral, Barcelona. 